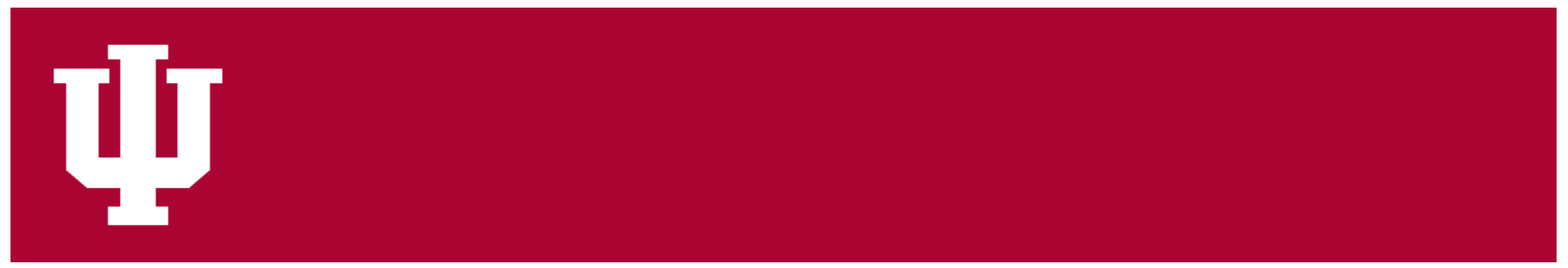

IUScholarWorks at Indiana University South Bend

\title{
Computer-Aided Music Distribution: The Future of Selection, Retrieval and Transmission
}

Duncan, Nancy Bogucki and Fox, Mark A.

To cite this article: Duncan, Nancy Bogucki and Fox, Mark A. "Computer-Aided Music Distribution: The Future of Selection, Retrieval and Transmission.” First Monday, ISSN 1396-0466, Valauskas, Edward J., 4 Apr. 2005. 1996 2005, journals.uic.edu, https://journals.uic.edu/ojs/index.php/fm/article/download/1220/1140?inline $=1$.

This document has been made available through IUScholarWorks repository, a service of the Indiana University Libraries. Copyrights on documents in IUScholarWorks are held by their respective rights holder(s). Contact iusw@indiana.edu for more information. 


\section{i (3) $s+m \boldsymbol{x} \tilde{\mathbf{n}} \mathbf{d} @ \boldsymbol{\eta}$}

PEER-REVIEWED JOURNAL ON THE INTERNET

Computer-aided music distribution: The future of selection, retrieval and transmission

\section{Abstract}

sThe Internet has made music more widely available and increased the convenience with which we can listen to music. We increasingly recognize that recorded music can take the form of digital files. The Internet and related technologies for music delivery have been made viable by advances in compression, data storage, and transmission technologies. To provide greater value to consumers, music labels need to make greater use of retrieval and selection technologies.

\section{Contents}

Introduction

The product of music

Why do we choose to experience music in different ways?

Technology and the provision of value to consumers

Conclusions

\section{Introduction}

Since the introduction of Napster and its followers the global music industry has experienced stagnant sales. Global sales of recorded music were down 1.3 percent for the first half of 2004, compared to the same period in 2003 (International Federation of the Phonographic Industry, 2004). The music industry - or, at least the major labels - have responded to stagnant revenues in several ways. First, the Recording Industry Association of America (RIAA) has attempted to educate consumers about the illegality of downloading pirated music (National Association of Recording Merchandisers, 2003). Major labels have also attempted to thwart music lovers' attempts at downloading from peer-to-peer services by spoofing downloadable music files so that music fans have trouble finding undamaged versions of songs (Maguire, 2003; Zolli, 2003). Most effectively, the Recording Industry Association of America (RIAA) has sued individual music file sharers. A recent report by the Pew Internet Project observed that:

"The percentage of online Americans downloading music files on the Internet has dropped by half ... since the Recording Industry Association of America (RIAA) began filing suits in September against those suspected of copyright infringement. Furthermore, a fifth of those who say they continue to download or share files online say they are doing so less often because of the suits." [1]

A common criticism of the recording industry's methods is that they are alienating customers and such a strategy can only come to grief [2]. Trade in recorded music is completely dysfunctional: suppliers are suing customers; some labels have colluded to fix prices [3]; and, consumers are foiling the suppliers' distribution systems wherever possible. Various industry commentators have suggested that the music industry's business model is obsolete [4]. We suggest that not only is the model for pricing and distribution outdated, but the industry's understanding of its product, even of its business, is as flawed as its customer relations practices.

A business model should optimize a firm's functioning in its current market environment in order to provide products or services that are in demand and competitive. This requires a clear understanding of the nature of the product and the characteristics of the market. The challenge to the music industry arises from the fact that over the past five years the World Wide Web has radically changed the market's perception of the nature of music itself and the services it demands. While the industry's lobby group, the Recording Industry Association of America, struggles to limit behaviors enabled by the Web, it is hard to imagine that that genie will ever go back in the bottle. As Michael Porter notes, "the winners will be those that view the Internet as a complement to, not a cannibal of, traditional ways of competing" [5].

Discovering a successful business model for the music industry may require going "back to basics," or to primary principles. Before we can propose updated sales or delivery constructs, we must clarify the product definitions and service expectations among music consumers. In
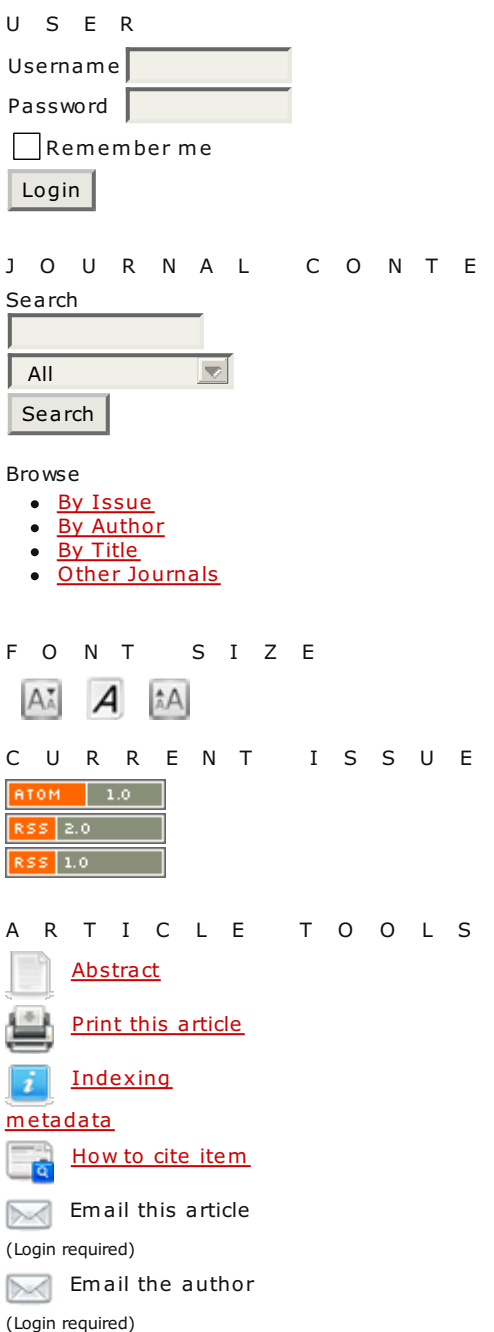

$\begin{array}{llllllllll}A & B & O & U & T & & T & H & E \\ A & U & T & H & O & R & S & & \end{array}$

Nancy Duncan

Mark Fox 
the case of music, primary principles underlying the product definition and market characteristics may be assessed through two elementary questions: (a) As a product, what characterizes music, and what are people willing to pay for? And, (b) why do we choose to listen to music in different ways (on the radio, live performance vs. pre-recorded music)? Once we have examined these questions, we look at the role that compression, data storage, and transmission technologies have played in altering the conceptualization of music as a product. We then look at how retrieval and selection technologies can help consumers obtain access to the music that they want to hear. This paper concludes with some observations about the role of technology in creating value for consumers.

\section{The product of music}

Let us begin with the distinction between music and music delivery. Music has been a form of human expression for millennia but until the last century it could only be delivered by live performance. The development of recording technology in the past century has given listeners the gift of autonomy. They are no longer dependent on musicians' location and performance times in order to listen to music. The degree of independence afforded consumers has evolved with music delivery devices. We have seen a century of continuous change in the delivery of music. This change has seen developments in the quality of recording, the durability of media (how long recordings will last for), space requirements of media, portability of media, interactive properties of media and the operating requirements of the media. Notably, since the 1950 s technological developments have resulted in music becoming increasingly portable and ubiquitous. Some examples include:

- eight tracks allowed people to take the music of their choice and play it in their cars

- audiocassettes (and the development of boom boxes) allowed people to take music and play it in public and private spaces; and

- the development of portable CD players and (most recently) mobile digitally compressed mode players such as the iPod allow individuals to carry increasing quantities of digital quantities of digital recordings on decreasingly sized devices. They can listen to music of their choosing virtually anywhere and during any activity.

Note that music autonomy is still constrained by reach, range, and by the static state of recordings. Reach refers to who can listen to a single playing of music at any one time. For example, in a live performance the reach is the concert hall; whereas for a pre-recorded song the reach encompasses radio airplay, playing digital downloads, CDs, etc. Range refers to compatibility of the recording mode with media available to play it. For example, vinyl records required a record player, whereas digital music files can be transferred to a wide variety of electronic devices, but not record players (computers, MP3 players). Finally, recordings are constrained by the fact that they are static (playing of the same performance will yield the same sound time and time again), whereas live performances can vary enormously and the performance can be an interactive event.

The development of MP3 technologies has enabled consumers to increasingly obtain music through their computers. Why is this? The simple answer would be that, using peer-to-peer services, such music can be obtained at no cost - so consumers may as well help themselves. For example, consider that a study of music downloaders in Germany found that the second major motive for using Internet music sites was the availability of free music (the first listed motive was a general interest in music) (Walsh, et al., 2003). Also, a recent U.S. report found that two-thirds of music downloaders did not care whether they were downloading copyrighted songs (Madden and Lenhart, 2003). Obtaining music online is also very convenient (it removes the time involved in traveling to a store), and gives consumers a huge selection to choose from. Traditional music stores are constrained by shelf space. The notion of giving consumers access to a catalog of music that they can pick and choose from is a means of providing value over and above what traditional music sales (of CDs) has traditionally been able to provide.

Obtaining music online also enables consumers to have more control over what they listen to. Up to the mid-1960s the primary unit of musical currency was the single - albums were created from several singles and typically contained a lot of "filler": however, during the 1960 s artists begun to conceptualize the creation of the album as a uniformed expression of some vision or theme. Many artists welcomed this move toward viewing the album as a whole rather than as just the sum of its parts. This gave artists greater creative flexibility - rather than telling one "story" in a three-minute pop song, they could have a series of songs that would fit together in some way so as to tell a more complex story (e.g., Pink Floyd's The Wall, or the Who's Tommy).

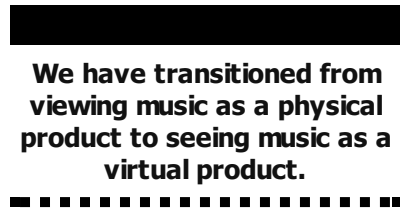

FM radio - at least initially - encouraged the development of album-oriented artists, owing to FM's willingness to play lengthy versions of songs that DJs on traditional top -40 radio were not interested in. However, in more recent years we have seen the re-emergence of the single (rather than the album) as the major focus of consumer interest in the music industry. The success of peer-to-peer services has shown us that individuals are happy to download individual songs; often picking their favorite songs off artists' albums. By ordering these songs together, consumers are creating their own listening experiences and bypassing the songst in which (many) artists envisaged their work would be listened to wh [6]. Some artists have refused to make their recordings available for commercial use on Internet music services because they object to consumers picking and listening to their songs in isolation and do not want to contribute to the demise of the album format [7]. (Arguably this is a little precious, as consumers can do this anyhow by skipping tracks on our CD players).

Most consumers feel that music should be deliverable to a wide variety of devices/locations, i.e, it should provide time and space independence. We should not have to transfer music from one device to another. Some central intermediary or personalized electronic library (referred to by some as a "celestial jukebox") should take care of the storing of "our music" (Mann, 2000). Music need not be viewed as a product/file, but can be seen as an entertainment experience that is provided from some central source (analogous to providers of pay-per-view movies in hotel rooms). Downloading music via a computer is still more cumbersome than some would like. Consumers who obtain music from a computer typically have to transfer it to another device (either directly, e.g., transferring to a device such as an iPod; or indirectly through, say, burning a CD and listening to it on a CD player). There is also 


\section{Why do we choose to experience music in different ways?}

We experience music in a variety of ways, most notably by listening to the radio, by listening to pre-recorded music, and by attending a concert. An examination of the benefits and costs of listening to music in each of these ways should give insights into how providers of pre -recorded music could provide additional value to consumers.

\section{Radio}

When we listen to radio we are provided with a listening experience that is largely dictated by radio programmers. Jarl Ahlkvist describes four programming strategies for radio. Each of these strategies is based on different points of view about the role of music programmers:

- The musicologist philosophy is based on the musical expertise and the ability of programmers to have an "ear" for what they would regard as quality music and artists. The expertise and personal taste of the programmer decide what music listeners are exposed to in order to "enlighten their listeners by exposing them to music they thin has integrity; music that they feel passionate about; music they think is good" [8].

- The surrogate consumer strategy views the programmers put themselves in the shoes of their listeners in order to reflect the tastes of their listeners. Central to this philosophy is bridging the gap between programmer and listener to such an extent that the programmer can intuit what listeners would like to hear.

- The programming professional philosophy is based upon gaining objective scientific evidence regarding the target audience's tastes. Under this philosophy music is viewed as akin to a product that needs to be sold based upon market research findings. In contrast to the musicologist and surrogate consumer strategies, the programming professional strategy does not rely upon programmers making their own judgments about music.

- The conduit strategy places emphasis upon "pushing" the music that music labels believe will be popular. The focus is on playing records that music labels - and radio programmers - believe will be hits with the station's demographic. Programmers using this philosophy view themselves as "trend-setters whose reputations for breaking hits, rather than stiffs are enhanced by record companies who cite them in their sales pitches to less cooperative programmers" [9].

The listening experience afforded by radio suits music listeners when they want to put little energy into what they are listening to (except perhaps deciding, in a general sense, what style or genre of music they wish to listen to). However, radio is a key means for consumers style or genre of music they wish to listen to). However, radio is a key means for consumers
to learn about new music that they may wish to buy. This is a key source of value that radio provides listeners.

Radio also provides a sense of community for listeners as they share in the listening experience with individuals of a similar demographic and oftentimes are provided with information about weather and news in their locale. Radio, however, has the problem of exposing us to music that we may dislike, and to advertising.

Radio is typically free, but adopts the so-called broadcasting model whereby station revenues are funded by advertising. The broadcasting model is based on the premise that the real value lies in the audience for music, rather than in the music itself, i.e., the audience is the product that is delivered to marketers (Fox and Wrenn, 2001). This shows that some consumers are willing to "put up with" advertising in order to be exposed to music. Consider also that, in the early days of radio that much of the revenues of companies, such as RCA, were generated from the sale of equipment - radio receivers [10]. Similarly, today companies such as Apple use music as a loss-leader in order to attract consumers to buying higher-margin listening devices (such as the iPod).

When we listen to the radio, we abdicate some of our choice to others, e.g., radio programmers, but we are still displaying some choice (choosing to listen to top-40 radio vs. a blues vs. a classical radio station). Why do some people abdicate their choice as to precisely what they listen to? First, it may be convenient. Like the Seth Brundle character in The Fly movie - or Steve Jobs of Apple, wearing the same clothes each day - it may save mental energy for tasks people would rather spend time on. The fact that radio is free (albeit often with the "cost" of listening to advertising) is appealing to many. However, a major benefit of having others choose what we listen to is that they may select music that we are largely already familiar with, and like, but also they may expose us to music that we had previously not heard. In short, we may discover new songs, artists, and musical genres thanks to the choices of radio programmers. This is arguably one reason why FM radio took off in the 1970 s - it exposed music lovers to music that they could not hear within the confines of the traditional three-minute pop songs played on Top 40 radio.

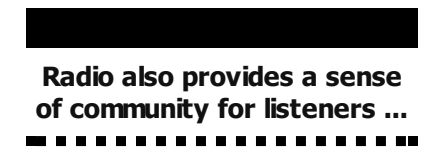

This tells us that one function that music delivery services should provide is the ability to provide playlists or pre-programmed choices. However, many of us may wish to be surprised by listening choices within specified genres (or, within, say, specific groupings of artists or themes). This necessitates the development of software that can predict - based upon your existing tastes and characteristics - what "new" music you will like to hear [11].

Clearly some developments have been made in the area of communal influences on the listening choices of individuals [12], but this appears to be an under-developed area with great potential.

\section{Concerts}

In North America alone the concert industry is valued at US $\$ 2.6$ billion per year, with around 37 million tickets being sold to the top 100 concerts (Pollstar, 2004). When we attend concerts we experience music with like-minded individuals. Attending concerts provides a sense of community that is greater than when listening to music alone. This sense of community and hero worship appears to be strongest for bands that have a fanatical following of their live 
performances, e.g., the Grateful Dead, Dave Matthews Band, or Phish. Oftentimes, consumers see concerts as a complement to pre-recorded music. At a concert we may learn things about an artist's music that we were hitherto unaware of, including gaining insights into the meaning behind an artist's work. We also gain the opportunity to share judgments on the performance skills of artists.

Audience members at concerts are engaging in a mass celebration of the work of performers who they admire. Concerts also permit audience members to hear performances of songs that have not yet been released, are seldom performed live, or are different in some way from the pre-recorded version. This is one reason why bootlegs of some artists are highly sought after. For emerging artists, whose ticket prices may be relatively low, attending concerts provides a means of sampling an artist's work without the commitment associated with buying pre-recorded music.

Tickets for concerts are priced largely upon the popularity of artists. Such tickets tend to be more expensive (at least for established artists) than the cost associated with purchasing pre -recorded music. Hence, for the top 100 tours of 2003 the average ticket price was US $\$ 50$ (Pollstar, 2004). Furthermore, concert goers appear to be relatively insensitive to concert ticket prices for major artists - between 2002 and 2003 the average ticket price charged by the top 10 concert performers increased from US $\$ 72$ to US\$84 (Pollstar, 2004). Many consumers appear willing to pay a premium for the uniqueness that attending a musical performance offers.

\section{Pre-recorded music}

Motives for buying pre-recorded music include the ability to listen to music when one wants and where one wants. However, pre-recorded music - particularly in traditional formats such as CDs, audio cassettes and vinyl provides - particularly for live, best of collections, or box sets - additional value in the form of lyrics, credits, and photographs. Pre-recorded music, particularly since the advent of CDs allows users to share music with their friends easier, and to customize collections of music (through burning CD-Rs, or transferring music to iPods).

The process of looking for music online vs. in a traditional music store is somewhat different. If we have a particular song we want to find, in a traditional music store one tends to look at music within a particular genre (e.g., country) and then search or browse within that category of music for albums containing that song and make a choice among these albums. In contrast, when looking for music online consumers will be able to search directly for the song in question. Hence, on the Internet the search process is more direct.

\section{Technology and the provision of value to consumers}

The digitization of music recordings is resulting in the deconstruction of the music industry's value chain. We are in a middle stage of a transition from discovering that sound can be stored on a disc - and consequently treasuring the disc - to discovering that music can be delivered via invisible media to anyone, almost anywhere. Digitizing music opened the delivered via invisible media to anyone, almost anywhere. Digitizing music opened the
floodgate for technology to transform the nature of the product and superannuated the entire value chain. We have quickly learned that we have acquired new power over the recorded music product. We can "rip" music on our CDs and store digitized music on our PCs. This, in turn, has enabled music consumers to refine the product's granularity from that of engraved collection of recordings to individual compositions (songs) or even phrases. With this capability, consumers' view of music as a product has changed forever, as have their expectations. In an interesting discussion of the decade's changes in how consumers view recorded music products, Charles Mann (2000) notes that listening behavior had already begun to change with the arrival of cassette tapes. Music enthusiasts have been generating their own recording collections since then. But the digitization of music has made the process vastly faster as well as yielding much less loss in audio fidelity. The first stage of this change in consumer behavior resulted in individualized CDs that listeners created for themselves. Today, however, leaders in finding the easiest way to enjoy music are willing to forego the $C D$ entirely. The $C D$ itself has become cumbersome; enthusiasts prefer smaller devices, with tiny or no additional components for storage. The ultimate vision of the "celestial jukebox" actually eliminates the need for the listener to carry a repository for the music files at all (Brown, 2000; Mann, 2000; Naughton, 2004). The vision of a celestial jukebox includes electronic transmission of music without a material record. Users of the celestial jukebox will need only speakers (presumably headphones) with receiver capabilities.

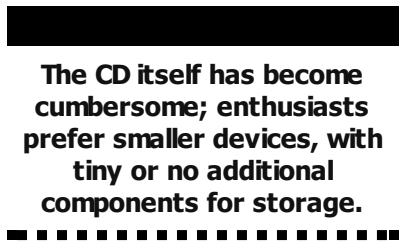

Four areas of information technology innovation are enabling the deconstruction of the music value chain and transforming the behaviors and demands of consumers. Characteristics of these technologies suggest the direction for the redesign of the obsolete music industry model. These technologies alter the nature of both the product and its distribution. They are: (a) compression of digital files; (b) storage and retrieval of the files; (c) the transmission of the files, and, (d) selection for playback. As we will discuss, the technologies are reducing much of the traditional production and distribution costs of recordings to near zero. We propose that it is in the problem of selection where the true opportunity for generating new value to customers lies.

\section{Data storage, compression and transmission}

Consumers "rip" music to their computers to gain the flexibility of managing each song or track separately from the others with which it is sold. The chief barrier to managing these digital files (electronically moving or storing them) lies in their size. A single song on a $C D$ may take up 25 to 50 megabytes of storage. The first obstacle to eliminating physical objects such as CDs and audio cassettes from the music value chain has been capacity. Consumers want to maximize the quantity of music that they can have with them without compromising sound quality. Data storage and file compression are both improving rapidly, and for many consumers have already made CDs a nuisance. 
While storage devices for digital files shrink in physical size, their capacity has grown immensely over the past decade. PC hard drives today offer anywhere from 40 to 800 gigabytes of storage. But, the PC is not portable and therefore does not support the "anytime, anywhere" listening option. Portable music storage devices include digital music players that contain their own hard drives and/or support portable storage devices, such as compact flash, secure digital, and USB flash. Portable digital music players such as Apple's iPod or the Rio Karma are available with 20 gigabyte internal hard drives. External devices (the size of a block of postage stamps) offer from one (USB flash) to 12 (compact flash) gigabytes of storage. Using these small, removable storage components allows manufacturers to make players even smaller. Creative's MuVo TX FM, a music player and FM radio currently on the market, measures 1.4 by 2.9 by 0.6 inches and weighs 1.5 ounces. One reviewer compares it in size to "a Zippo lighter with an LCD screen and buttons" (Broida, 2004). The device reads USB flash memory devices, so users' quantity of music available is limited by the number of postage stamp-sized blocks they are able or willing to carry.

The near future of storage devices continues to be increasing storage capacity while reducing physical size of the storage device. There is every indication that this trend will continue. For example, IBM's Millipede technology enables thermo-mechanical storage which is achieving data densities of hundreds of gigabytes per square inch. IBM expects Millipede storage cards to be smaller than current flash devices, require less power, and to cost as a little as one fifth the price of today's higher-end flash devices. They will vastly increase the capacity and capabilities of such small, handheld devices as PDAs, smart phones, and, conceivably, music players. Millipede storage cards may be on the market as early as 2005 (Vinas, 2003).

Longer range development in data storage is taking place in physics labs. Universities in Toronto and Vienna are developing techniques for "entangling photons" in order to shorten their wavelengths to increase the inscription capacity of light. With the shorter wavelength, lasers can inscribe a great deal more digital information on disks (Hogan, 2004).

\section{Compression}

Another way to expand storage capacity is to reduce the size of music files. Today, digital music files can be stored in a number of formats to either maximize fidelity or to minimize storage requirements. One of the oldest - and probably best-known compression/decompression formats (codecs) is MP3. It is popular with users for its near-CD quality and relative high speed of encoding and decoding. It is less popular with the music industry because it lacks controls to prevent copying.

As the demand for compact digital music players has exploded, new technologies for compressing the files have been developed and introduced, e.g., MP3, AAC, ADPCM, FLAC, OGG, and VOF. These technologies differ by compression rate and loss of audio quality. They also vary by the amount of power required to code or decode them and the bit rate, or number of bits per second used in the audio file. While the technology for audio file compression continues to improve, the usefulness is compromised by incompatibilities among them

"Unfortunately, digital audio is more complicated than it has to be. Both the computer and $C D$ industries would stand to gain from adopting more universal standards and working toward interoperability. Unfortunately, there are too many incompatible formats, too many exposed settings and important terms to learn, and too many companies trying to lock you into using their own tools" (Cross, 2004).

\section{Transmission}

Delivery of digital music requires transmission of the files via electronic media to some form of electronic receiver, either for storage or playback. To the chagrin of the music industry, consumers quickly discovered that the Internet provides a cheap and efficient media for file transfer. Peer-to-peer networks have become the most notorious technology for digital file distribution, but as intermediaries such as Apple, WalMart and Amazon have demonstrated, digital files can be sold over the internet and simply downloaded to the consumer's computer quite efficiently.

The chief constraint on transmission of digital files is capacity. The larger the digital file, the longer it takes to transmit. Consequently, information technology research continuously seeks ways to increase the reach and the capacity of network infrastructure. To date, consumers' access to the Internet depends largely on wired connections. Music is downloaded via a PC -Internet connection, stored on the PC hard drive, and then possibly transferred to one of the storage devices discussed earlier. The consumer's desire to listen to music anywhere and at any time is constrained by the cables, either telephone or coaxial, by which they could access the Internet. The problems with these two media are capacity and cost. Capacity for electronic transmission of digital files is affected by two variables: the size of the file - which, in the case of music, is reduced through compression - and the bandwidth of the transmission media. While telephone access is comparatively inexpensive, its data transmission capacity is so limited that downloading large digital files is very time-consuming and prone to interruption. Coaxial media have greater transmission capacity and therefore work well for transmitting music files, but it has been comparatively expensive for average consumers. Coaxial cable is still not even available in some rural areas of the country. Both of these media, however, have the constraint for listeners of the wires themselves. When digital music is only available where there are wires, the "anytime, any place" objective is thwarted.

Today, wireless access to the Internet is growing, primarily through "Wi-Fi," or 802.11 standard wireless local area networks. These networks are rapidly becoming commonplace on college campuses; consequently today's college students are quickly learning to expect on college campuses; consequently today's college students are quickly learning to expect area networks (WLAN) are extending our access to the Internet anywhere that "hot spots" are generated. These are increasingly common in homes, in fast-food restaurants, motels, coffee shops, airports, and other public places as well as on university campuses. The service is often free. Through these WLANs, users download digital files to laptops, personal digital assistants (PDAs) or other portable receivers.

While the WLAN technology retains range limitations, other transmission technologies are emerging that will extend the range of wireless transmission immensely. XM satellite radio, the Wireless Metropolitan Area Network technology (also known as Wi-MAX and 802.16), and $4 \mathrm{G}$ telecommunications, all offer exciting new media for digital audio file transmission virtually anywhere. The transmission range for WiMax is 30 miles. Although the technology and initial standards are well established today, implementations are only beginning. So far, the major telecommunications carriers have not shown much interest in diversifying into this area of telecommunications services. Consequently, its implementation is largely in the hands of community leadership and IT network service providers (Lawson, 2004). One market research firm specializing in wireless technologies anticipates that annual sales of WiMAX chipsets will reach 2.2 billion by 2008 . They further anticipate that the combined technologies of Voice over IP and WiMAX will "will eliminate and replace a complete stratum of our infrastructure that has served us so well for over one hundred years: the telephone" (4G, 2004). 
4G is the emerging wireless telecommunications technology that will support voice and data transmissions at the same rate as wired Local Area Networks (100 Mbps). A year ago predictions were that $4 \mathrm{G}$ should not be expected until 2010 , but the predictions are being lowered now to as early as 2006 . There is a pressing demand for bandwidth capacity that will enable us to stream data, voice, and video real-time via our wireless phones, and to talk over these phones to anyone in the world via the Internet, rather than the current cell or wired telephone infrastructure. According to the Fourth Generation Mobile Forum, the standards body designing 4G architecture,

"In 2000, there were only eight organizations involved in 4G R\&D; In 2002, over 200 companies and research institutions on 4G projects; In 2003, the 4G community expanded to over 2500 bodies worldwide; By 2008 over $\$ 400 \mathrm{~B}$ will be invested for 4G Mobile." (4G, 2004)

The rapid development of both WiMAX and $4 \mathrm{G}$ telecommunications predict a near future in which music will only be easier to transfer across the Internet, not just in the United States, but around the world.

\section{Selection}

From our earlier discussion of the development of music formats, it is clear that from the point of view of consumers, music is simply vibrations in the air [13]. The smaller and lighter the devices that generate these vibrations the better - even until the media completely disappear. However, even if the delivery devices morph and reduce in size, the product itself remains the same. A key feature of the product - whatever form it takes - is listening autonomy. One key feature of the delivery devices that are based upon downloading music from the Internet (e.g., iPods) is that they allow us to listen to the music that we select, when we chose, and where we choose. The development of music delivery technologies shows that consumers value time independence (being able to listen to music when they want) and that the development of music delivery devices has continuously increased our space independence (i.e., our ability to listen to music wherever we would like). Also, recent developments (such as MP3 players) provide autonomy of content by providing listeners with the ability to create their own playlists.

On a more sophisticated level, researchers are working on electronic music distribution that will enhance the ability of consumers to find music in ways that are convenient and meaningful to them. Textual characteristics of music, such as the composer and performer, as well as socially defined characteristics such as genre, are being coded into some digitization formats, such as MIDI and MPEG7 files. Increasingly digital music technology is finding ways to imbed more intrinsic characteristics of music into the digital file.

For many consumers, music retrieval may simply involve a typed, menu-driven, or ora request for a particular song, by a particular artist. More sophisticated music request technologies in development will allow consumers to search for music by humming (Ghias, et al., 1995), singing (Pardo, et al., 2004), or playing the music they are interested in hearing (Pickens, et al., 2003).

Selection of music to listen to is a question of preference. Preference, however, is not a simple construct. First, preference is variable. At times it may be clearly defined, while at other times it may be ill-defined. That is, sometimes we know exactly what we want to listen to, but at others (and for many of us, much more frequently) we should like to listen to music but don't have specific choices clearly defined in our minds. The degree to which our preference is defined at all depends on numerous factors of which we may or may not even be aware. At times genre may be the dominant variable of preference while at others, composer, performer, or instrument may carry more weight. In the past, access to only a few recordings simplified the selection problem; as access to recordings explodes, so do the immediate options for music selection, and the selection options for combinations approach infinity. If, as technology seems to suggest, each listener is to hear what she wants, but only what she wants, wherever and whenever and however she wants, music file management becomes a non-trivial problem. Delivering some music is becoming extremely easy and low cost. Providing the listener with just the right music is a much greater challenge.

In the past, technology permitted us only two major choices in selecting music: broadcast, in which we have little control of selection but access to a much larger collection of music than our own, or one of the recordings we own. The choice, for most of us, was manageable partly our own, or one of the recordings we own. The choice, for most of us, was manageable partly
by virtue of the limitations. We acquired recordings that seemed likely to match future defined preferences; we listened to the radio when our preferences were ill-defined. The nature of mass-production and distribution prohibited the recording labels from offering listeners customized playlists. The problem of arranging a continuous stream of music according to defined preferences was insurmountable until the technology by which listeners could re -record their music onto a secondary medium arrived. The broadcast selection satisfied our need for a stream of music, "surprise" in listening to music (since the DJ selects the playlist) and exposed us to new music.

The digitization of music has made customizing our stream of music selections not only feasible but technically easy. However, as the body of music to which we have access grows, the task of selecting and ordering music becomes increasingly complex and time-consuming. The objective of the exact music we want, and only music we want, where we want, when we want, and in the mode we want, consequently is mainly threatened by the complexity of the selection and order tasks, and by our own limited rationality. Given the quantity of music available to us, we probably lack the attention span, the memory, or the time to fully analyze available to us, we probably lack the attention span, the memory, or the tim
all the variables related to preference and all the musical options available.

Also, designing playlists for ourselves, from our own collections, eliminates the possibility for the elements of surprise or of discovery. Consequently, delivery of music according to our preference of the moment - especially when ill-defined - requires "some sort of digital mapping between music and people" [14]. In other words, customized music delivery requires technology that knows us and music better than we know either, ourselves. Fortunately, emerging information technologies for personalized "content management" and "electronic music distribution" are moving forward briskly. They are drawing upon such computer technology fields as data mining and various forms of artificial intelligence.

Preference analysis can be conducted over three domains. First, defined preferences are identified through numerous means of conscious introspection. We list out what we know about our attitudes towards specific musical compositions. Music enthusiasts commonly group selections by personal classification strategies (working out music, car music, party music, self-pity music). We may generate lists on our own; we may respond to surveys, rating or ranking the music they list; we may give feedback about music after we listen to it. Variables such as our activities at the time we enjoyed certain music may also be stored for further analysis. Collection of this sort of data is technologically not difficult. Data collection instruments or devices and electronic databases are all that's needed to store and query such data. Many databases of this nature have already been developed. Moodlogic.com claims to have a database of "more than a billion survey answers" about music preferences collected from "tens of thousands" of contributors. 
preferences. One domain involves identifying patterns of preferences in a very large database containing many listeners' interests and tastes and applying those defined patterns to predict an individual's likely preferences. The other involves identifying patterns in the preferred music itself. Defining our ill-defined preferences may draw upon such information sources as previously established preference data, preference patterns of other music listeners, and personal behavior patterns (correlations between activity and musical genre preferences, mood and musical tempos, even weather and instrumentation, for examples), but it may also draw upon information gleaned from the music itself.

Collaborative filtering is the process of using data from a large number of music listeners to develop generalizations about preference patterns. MoodLogic's database enables it to search for patterns among listeners that help to classify music in more ways and to anticipate individual preferences by profile matching. These generalizations help the owners of the data to predict music listeners' preferences accurately enough that the listeners find the service useful. In this environment of community behavior analysis, music characteristics are established in terms of standard social music classifications such as genre, composer, performing artist, instruments, etc. In current research on collaborative filtering and related electronic music distribution methods, these characteristics are simply identified by experts and coded into the data management programs (e.g., Field, et al., 2001; Pachet, 2003). This sort of technology is used in today's most common music recommendation systems. In practice, this technology may rely on fairly simple database query results or may result from more sophisticated technology such as neural networks.

\section{Conclusions}

Business models for music delivery need to provide flexibility to consumers - to give them the ability to use their own creativity and whims to There is still demand for CDs but arguably even more demand for the more finely articulated choices of the individual, which mandates alternate selection and delivery modes. The music industry has tended to react extremely slowly to technological developments, and has been accused of having "a long history of technophobia" (Seabrook, 2003). In particular, the Big Five labels (now the Big Four) record labels were slow to realize the potential of the Internet. Even today the industry largely sees the product it sells as a physical item, typically a compact disc. Until relatively recently, viewing music as a physical item has been convenient, and profitable, for the music industry. Historically, music labels have used the introduction of new music formats to grow revenues - with many consumers replacing their existing catalog of music with a new format that provides increased fidelity, convenience, and flexibility. As music companies continue to control their product through its physical production and subsequent distribution their chief use of emerging information technology has been Digital Rights Management (DRM). Their emphasis is on finding ever more effective ways to make recorded music less accessible. The longer the industry clings to a model of limiting access and flexibility, the longer it leaves an unexploited market to create new delivery models that - for better or for worse - redefine the industry.

This inertia is, perhaps, understandable given that viewing music as a service to be delivered via the Internet would necessitate a dramatic change in thinking and infrastructure. However the potential for music as a service appears significant, if developed with well-conceived business models that provide value to consumers over and above that offered by free downloads. The challenge for the music industry is to ensure that it provides this value.

It is fair to say that current business models are poor at meeting consumers' emotional needs (a key reason for listening to music in the first place). Some technologies, e.g., iPods allowing users to create playlists (which could include playlists for different "moods"); however, for the delivery business to be successful in this regard it needs to be more interactive and to have a memory. By more interactive, we mean that users should be able to indicate what songs the like/dislike (and in what circumstances). By having a memory, we mean that users should be able to indicate their state of mind - or have devices play music based on factors such as time-of-day and previous likes/dislikes. In essence, as well as giving users the ability to choose music song-by-song, technology should be able to create customized play lists based upon our previous listening experiences, the activity we are engaged in, the time of day, and our emotional state (or our desired emotional state).

\section{About the authors}

Nancy Bogucki Duncan is Assistant Professor of Decision Sciences at Indiana University South Bend.

E-mail: nbduncan [at] iusb [dot] edu

Mark A. Fox is Professor of Management \& Entrepreneurship at Indiana University South Bend.

Web: http://mypage.iusb.edu/ mfox1

Direct comments to mfox1 [at] iusb [dot] edu

\section{Notes}

1. Madden and Lenhart, 2004, p. 1.

2. See, generally, Nick Wingfield and Ethan Smith, 2003. "The high cost of sharing," Wall Street Journal ( 9 September), at http://wsjclassroom.com/onlinemusic/story01.htm. Various Street Journal ( 9 September), at http://WSjclassroom.com/onlinemusic/story01.htm. Various major record labels. For example, http://www.stopriaalawsuits.com/, suggests that music lovers: (1) Boycott music sold by the major record labels; (2) Tell their friends, family, and others why buying music produced by the major labels is unethical; (3) Support the individuals and families that are being sued; and, (4) Support independent musicians and record labels. Also see http://www.boycott-riaa.com/.

3. See Ashlee Vance, 2003. "Labels charged with price-fixing," The Register (29 July), at http://theregister.com/content/6/32048.html; Also see Federal Trade Commission, 2002. "Administrative law judge bars distributors of Three Tenors Media from agreeing to 'fix, raise, or stabilize' prices" (28 June), at http://www.ftc.gov/opa/2002/06/3tenors.htm.

4. Matt Cole proposes that "Music traders are under attack from the corporate music industry, 
which would rather keep its obsolete business model and centralized control of music dissemination, than update to a more decentralized, customer- and band-friendly, if less controllable model." Matt Cole, "Exploring music trading," BiblioTech, at

http://www.sir.arizona.edu/lso/cole2.htm. Also see Oliver Descoeudres, 2003. "Can the music

industry change?" Technology \& Business Magazine (13 August), at

http://www.zdnet.com.au/news/communications/0,2000061791,20277194,00.htm.

5. Porter (2001), p. 63.

6. It appears that music intermediaries have so far neglected the potential of bundling music - groups of singles - for sale. Bakos and Brynjolffson observe that products such as music can be thought of as a digital information good, which can be provided at very small additional marginal cost. These authors demonstrate that, "by offering a menu of different bundles aimed at each market segment, bundling makes traditional price discrimination strategies more powerful by reducing the role of unpredictable idiosyncratic components of valuations" (p. 1613)

7. See, for example, http://maccentral.macworld.com/news/2003/07/03/metallica/ and http://homepage.mac.com/spsmyth/iblog/C $382320337 /$ E963930192/.

8. Ahlkvist (2001), p. 346.

9. Op.cit., p. 351

10. See Hanson (1998).

11. Alternatively, John Seabrook (2003) suggests that the Artist \& Repertoire staff of today may perform this function:

"Arguably, the most important function that record-industry professionals perform .... is filtering through the millions of aspiring artists who think they can sing or play and finding the one or two who really can. Record men of the future might not need to do A\&R; they might not even make records. They may prepare monthly playlists of new songs or artists that will be beamed wirelessly to your portable MP3 player."

12. For example, Amazon's service that provides recommendations for music that you may like to purchase. Also, in its initial incarnation Napster offered a Hot List feature. More recently, Apple's iTunes offers recommendations for future listening, based upon current interests.

13. As Peter Earl (2001) observes "[f]ormally speaking, music is nothing more than an organized flow of information, capable of being relayed to consumers via a variety of delivery modes" (p. 354).

14. Pachet, et al. (2004), p. 1037

\section{References}

Jarl A. Ahlkvist, 2001. "Programming philosophies and the rationalization of music radio," Media, Culture and Society, volume 23, number 3, pp. 339-358.

Yanis Bakos and Erik Brynjolfsson, 1999. "Bundling information goods: Pricing, profits, and efficiency," Management Science, volume 45, number 2, pp. 1613-1630.

Rick Broida, 2004. "CNET preview," New York Times (28 June), at http://cnet.nytimes.com/Creative_MuVo_TX_FM_256MB/4505-6490_7-30906242-2.html accessed 1 April 2005.

Janelle Brown, 2000. "The jukebox manifesto," Salon (13 November), at http://dir.salon.com/tech/feature/2000/11/13/jukebox/intex.html, accessed 10 November 2004.

Jason Cross, 2004. "Digital audio primer," ExtremeTech (26 January), at http://www.extremetech.com/article2/0,1558,1460716,00.asp accessed 10 November 2004

Peter E. Earl, 2001. "Simon's travel theorem and the demand for live music," Journal of Economic Psychology, volume 22, number 3, pp. 335-358.

Adam Field, Pieter Hartel, and Wim Mooij, 2001. "Personal DJ, an architecture for personalised content delivery," WWW10 Hong Kong (1-5 May), at http://www10.org/cdrom/papers/384/, accessed 1 April 2005

4G (Fourth Generation), 2004. "Fourth Generation Mobile Forum," at http://www.delson.org/4gmobile/main.htm, accessed 10 November 2004

Mark A. Fox and Bruce Wrenn, 2001. "A broadcasting model for the music industry," International Journal on Media Management, volume 3, number 2, pp. 112-119.

Asif Ghias, Jonathan Logan, David Chamberlin, and Brian C. Smith, 1995. "Query by humming - Large musical information retrieval in an audio database," Proceedings of the Third ACM International Conference on Multimedia San Francisco (5-9 November), at http://www.cs.cornell.edu/Info/Faculty/bsmith/query-by-humming.html, accessed 1 April 2005.

Ward Hanson, 1998. "The original WWW: Web lessons from the early days of radio," Journal of Interactive Marketing, volume 12, number 3, pp. 46-56.

Jenny Hogan, 2004. "Quantum trick may multiply CD capacity," New Scientist (12 May), at http://www.newscientist.com/news/print.jsp?id=ns99994988, accessed 10 November 2004.

International Federation of the Phonographic Industry, 2004. "IFPI releases world recorded music sales figures for first half of 2004," at http://www.ifpi.org/sitecontent/press/20040930.html, accessed 10 November 2004

Stephen Lawson, 2004. "WiMax starting to make its move," Network World Fusion (7 June), at http://www.nwfusion.com/news/2004/0607wimax.html, accessed 10 November 2004

Mary Madden and Amanda Lenhart, 2004. "Sharp decline in music file swappers: Data memo from PIP and comScore Media Metrix," Pew Internet \& American Life Project (4 January), at http://www.pewinternet.org/PPF/r/109/report display.asp, accessed 10 November 2004.

Mary Madden and Amanda Lenhart, 2003. "Music downloading, file-sharing and copyright: A Pew Internet Project data memo," Pew Internet \& American Life Project ( 31 July), at http://www. pewinternet.org/reports/toc.asp?Report=96, accessed 10 November 2004. 
James Maguire, 2003. "Hitting P2P users where it hurts," Wired (13 January), at http://www.wired.com/news/digiwood/0,1412,57112,00.html, accessed 10 November 2004

Charles C. Mann, 2000. "The heavenly jukebox," Atlantic Monthly (September), at http://www.theatlantic.com/issues/2000/09/mann.htm, accessed 10 November 2004

National Association of Recording Merchandisers, 2003. "Recording academy to launch research-based public education campaign addressing the value of paying for music," (4 December), at

http://www.narm.com/Content/NavigationMenu/Media Center/Industry News/NARASCampaign.htm, accessed 10 November 2004

John Naughton, 2004, "The joys of the celestial jukebox," Guardian Weekly (4 July), at http://www.quardian.co.uk/print/0,3858,4962893-110428,00.html, accessed 10 November 2004

Francois Pachet, 2003. "Content management for electronic music distribution," Communications of the ACM, volume 46, number 4, pp. 71-75.

Francois Pachet, Amaury La Burthe, Aymeric Zils, and Jean-Julien Aucouturier, 2004. "Popular music access: The Sony music browser," Journal of the American Society for Information Science and Technology, volume 55, number 12, pp. 1037-1044.

Bryan Pardo, Jonah Shifrin, and William Birmingham, 2004. "Name that tune: A pilot study in finding a melody from a sung query," Journal of the American Society for Information Science and Technology, volume 55, number 4, pp. 283-300.

Jeremy Pickens, Juan Pablo Bello, Giuliano Monti, Tim Crawford, Matthew Dovey, Mark Sandler, and Don Byrd, 2002. "Polyphonic score retrieval using polyphonic audio queries: A harmonic modeling approach," Journal of New Music Research, volume 32, number 2, pp. 223 $-236$.

Pollstar, 2004, "2003 year end business analysis," Pollstar (12 January), pp. 8, 10.

Michael E. Porter, 2001. "Strategy and the Internet," Harvard Business Review (March), pp. 63 -78 .

John Seabrook, 2003. "The money note," New Yorker (7 July), at http://www.newyorker.com/fact/content/?030707fa fact2, accessed 10 November 2004.

Tony Vinas, 2003. "Technologies of the year - IBM's Millipede march," Industry Week (1 December), at http://www.industryweek.com/CurrentArticles/Asp/articles.asp? ArticleId $=1521$ accessed 10 November 2004

Gianfranco Walsh, Vincent-Wayne Mitchell, Tobias Frenzel, and Klaus-Peter Wiedmann, 2003. "Internet-induced changes in consumer music procurement behavior: A German perspective," Marketing Intelligence \& Planning, volume 21, number 5, pp. 305-317.

Andrew Zolli, 2003. "Monsters of rock," Wired, volume 11, number 9, at http://wwW.wired.com/wired/archive/11.09/starthtml?pg=12, accessed 10 November 2004

\section{Editorial history}

Paper received 6 December 2004; accepted 21 March 2005

\section{@}

This work is licensed under a Creative Commons License.

Computer-aided music distribution: The future of selection, retrieval and transmission by Nancy Bogucki Duncan and Mark A. Fox

First Monday, Volume 10, Number 4 - 4 April 2005

http://journals.uic.edu/ojs/index.php/fm/article/view/1220/1140

† SHARE

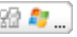

A Great Cities Initiative of the University of Illinois at Chicago University Library.

(c) First Monday, 1995-2013. 